\title{
Message from Editor-in-Chief
}

\section{O. Ortmann}

Published online: 5 July 2013

(C) Springer-Verlag Berlin Heidelberg 2013

Thank you to Prof. Hans Ludwig and Prof. Klaus Diedrich.

The current impact factor of Archives in Gynecology and Obstetrics is 1.33. As shown in Fig. 1, the rise of the impact factor of the journal is steady and impressive. This recent success of the journal is the result of the great work performed by $\mathrm{H}$. Ludwig, Basel, Switzerland and K. Diedrich, Lübeck, Germany, who served as Editors-inChief from 1998 to 2010 and 2013, respectively. These two pioneers in the field together with outstanding staff, editors, associate editors, editorial board members and reviewers have clearly increased quality and reputation of the journal. A large number of scientists have reviewed thousands of manuscripts, another contribution that is very important for the success of the journal.

The whole team is grateful to $\mathrm{H}$. Ludwig and K. Diedrich for their outstanding work.

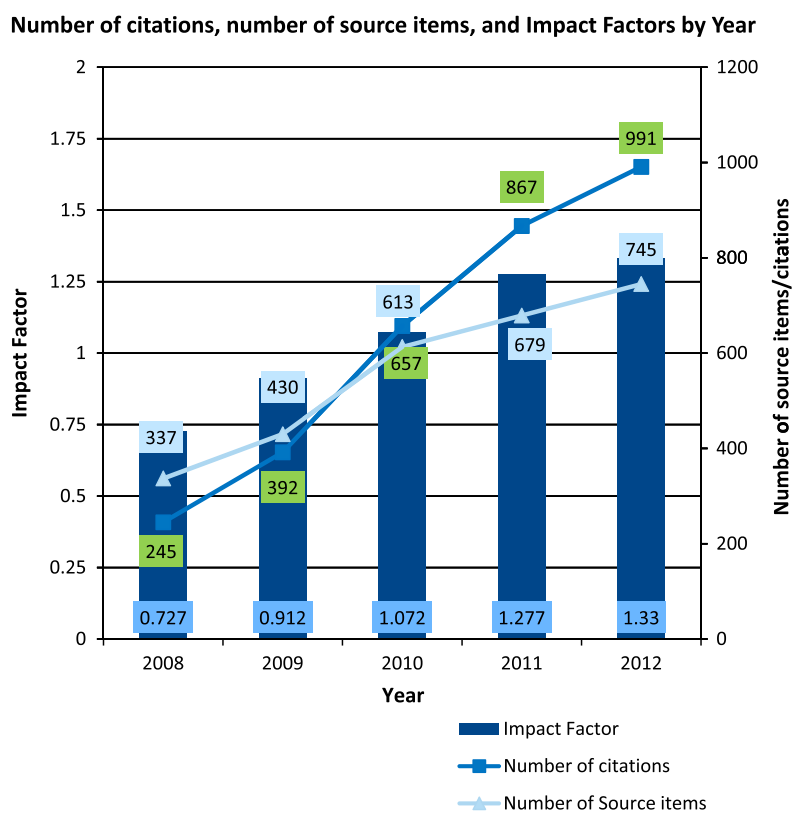

Current Impact Factor of 1,330

(Rank 55 out of 77 in the category "Obstetrics and Gynecology“)

Fig. 1 Impact factor trend graph
O. Ortmann ( $\square)$

University Medical Center Regensburg,

Department of Gynecology and Obstetrics,

Landshuter Str. 65, Regensburg, Germany

e-mail: olaf.ortmann@klinik.uni-regensburg.de 